\title{
Polymerization of Aromatic Aldehydes. VII. Cyclopolymerization of $o$-Formylphenylacetaldehyde and Formation of a Cyclic Trimer
}

\author{
Sanae TAgami, Takashi Kagryama, and Chuji Aso \\ Department of Organic Synthesis, Faculty of Engineering, Kyushu University, \\ Fukuoka, 812, Japan.
}

(Received October 19, 1970)

\begin{abstract}
Polymerization of $o$-formylphenylacetaldehyde was carried out with various catalysts. The polymer obtained below $-60^{\circ} \mathrm{C}$ with $\mathrm{BF}_{3} \mathrm{OEt}_{2}$ catalyst was soluble in common organic solvents and was confirmed as a cyclopolymer composed of 6-membered cyclized units. The cationic cyclization step in the cyclopolymerization of $o$-formylphenylacetaldehyde was inferred to proceed through a intermediate or concerted scheme similar to those proposed for the cationic propagation of $o$-phthalaldehyde.

On the other hand, under cationic polymerization conditions over $-40^{\circ} \mathrm{C} o$-formylphenylacetaldehyde gave a cyclic trimer $\left(\mathrm{mp} 284-285^{\circ} \mathrm{C}\right)$ possessing fused ring ether, which had no aldehyde group. Interestingly, the cyclic trimer was also produced from the polymer by treatment with $\mathrm{BF}_{3} \mathrm{OEt}_{2}$ in methylene dichloride.

Cyclopolymers of $o$-formylphenylacetaldehyde were also obtained with Ziegler catalyst at 0 and $-78^{\circ} \mathrm{C}$, and with $t$-BuOLi catalyst at $-78^{\circ} \mathrm{C}$.
\end{abstract}

KEY WORDS Cyclopolymerization/Cationic Polymerization/Ring Formation / Cyclooligomerization / $o$-Formylphenylacetaldehyde / Dialdehyde / Cyclopolymer / Cyclic Trimer/Poly (o-Formylphenylacetaldehyde)/ Polyacetal

In contrast to the difficulty in obtaining polymers from benzaldehyde and its derivatives, $o$-phthalaldehyde was found to give a cyclopolymer readily, as shown in eq $1 .{ }^{1,2}$

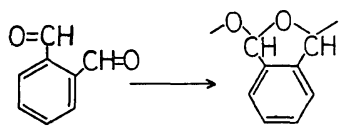

The driving force for the polymerization was ascribed to the ease of intramolecular cyclization, and it was emphasized that the aromatic aldehyde group could participate in polymerization when ready formation of the cyclic unit by cyclopolymerization was expected. This presumption was substantiated by the fact that $o$-vinylbenzaldehyde gave a cyclopolymer with cationic catalysts. ${ }^{3}$

That investigation is now extended to the polymerization of $o$-formylphenylacetaldehyde, a monomer which possesses aromatic and aliphatic aldehyde groups, and is believed to undergo formation of the six-membered ring unit. It was of particular interest to compare the reactivities of these aldehyde groups. The isolation of $o$-formylphenylacetaldehyde was not reported, though synthesis of isobenzpyrylium ferric chloride without isolation of this dialdehyde was reported by Blount and Robinson. ${ }^{4}$ This paper describes the polymerization of $o$ formylphenylacetaldehyde with various catalysts and the formation of a cyclic trimer under cationic conditions.

\section{EXPERIMENTAL}

Materials

$o$-Formylphenylacetaldehyde was prepared from indene as follows

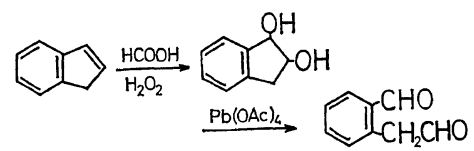


The cleavage reaction of trans-indane-1, 2-diol to dialdehyde was carried out in accordance with the procedure reported by Blount and Robinson, ${ }^{4}$ and $o$-formylphenylacetaldehyde was able to be isolated at relatively high yield.

trans-Indane-1, 2-diol. To a mixture of $500 \mathrm{ml}$ of $85 \%$ formic acid and $50 \mathrm{ml}$ of an aqueous solution of $30 \%$ hydrogen peroxide was added dropwise $58 \mathrm{~g}(0.5 \mathrm{~mol})$ of indene over a period of $30 \mathrm{~min}$ at a temperature below $30^{\circ} \mathrm{C}$. The reaction mixture was then stirred at room temperature for $3 \mathrm{hr}$, and approximately $1 \mathrm{~kg}$ of cracked ice and $0.5 \mathrm{~kg}$ of anhydrous potassium carbonate were added. The yellowish white precipitate was filtered and the solid product was saponified in $200 \mathrm{ml}$ of $5 \%$ aqueous sodium hydroxide at $50^{\circ} \mathrm{C}$ for $30 \mathrm{~min}$. The brownish crude diol product, which was separated by cooling the solution to $0^{\circ} \mathrm{C}$, was collected by filtration and recrystallized from benzene: yield, $25 \%$; mp $100-101.5^{\circ} \mathrm{C}$ (lit. ${ }^{5} \mathrm{mp} 102-$ $104^{\circ} \mathrm{C}$ ).

o-Formylphenylacetaldehyde. To a solution of $25 \mathrm{~g}(0.17 \mathrm{~mol})$ of indane-1, 2-diol in $300 \mathrm{ml}$ of dry benzene containing $2 \mathrm{ml}$ of pyridine was added $80 \mathrm{~g}(0.18 \mathrm{~mol})$ of lead tetraacetate at 20 $25^{\circ} \mathrm{C}$ over a period of $10 \mathrm{~min}$ while stirring. The reaction mixture was stirred for an additional $10 \mathrm{~min}$ and then filtered. The filtrate was washed with an aqueous solution of sodium chloride and then with $5 \%$ aqueous potassium carbonate, and dried over anhydrous sodium sulfate. Benzene was evaporated in vacuo and the residual colorless liquid was purified by fractional distillation in a high vacuum: yield, $64 \%$; bp $77-78^{\circ} \mathrm{C}(0.03 \mathrm{~mm})$; mp ca. $24^{\circ} \mathrm{C}$. The IR spectrum showed peaks at 2830 (weak, $\nu_{\mathrm{CH}}$ of aliphatic aldehyde), 2760 (weak, $\nu_{\mathrm{CH}}$ of aromatic aldehyde), 1730 (strong, $\nu_{\mathrm{C}=0}$ of aliphatsc aldehyde), 1700 (strong, $\nu_{\mathrm{C}=0}$ of aromatic aldehyde), 1600 (weak, phenyl), 1582 (medium, phenyl), and $750 \mathrm{~cm}^{-1}$ (strong, phenyl). The NMR spectrum $\left(\mathrm{CCl}_{4}\right)$ exhibited peaks at 10.05 (aromatic aldehyde proton, singlet), 9.76 (aliphatic aldehyde proton, triplet), 7.0-7.8 (phenyl proton, multiplet), and $3.96 \mathrm{ppm}$ (methylene proton, doublet). The area ratio of these peaks $(1.0: 1.1: 4.0: 1.9)$ was close to the theoretical value $(1: 1: 4: 2)$.
Anal. Calcd for $\mathrm{C}_{9} \mathrm{H}_{8} \mathrm{O}_{2}: \mathrm{C}, 72.95 ; \mathrm{H}, 5.44$. Found: C, 72.70; H, 5.45.

2, 4-Dinitrophenylhydrazone of the dialdehyde, consisting of orange-colored needles, was recrystallized from dimethylformamide, $\mathrm{mp}$ 259$260^{\circ} \mathrm{C}$ (decomposed).

Anal. Calcd for $\mathrm{C}_{21} \mathrm{H}_{15} \mathrm{~N}_{8} \mathrm{O}_{8}: \mathrm{C}, 49.61 ; \mathrm{H}$, 3.17; N, 20.03.

Found: C, 50.77; H, 3.47; N, 20.12.

$\mathrm{BF}_{3} \mathrm{OEt}_{2}$ was purified by distillation under nitrogen. $\mathrm{TiCl}_{4}$ was heated at $100^{\circ} \mathrm{C}$ with copper powder and distilled. $\mathrm{AlEt}_{3}$ (Ethyl Corp., U.S.A.) was used without further purification. $t$-BuOLi was prepared by the reaction of dry $t$ butyl alcohol with lithium in benzene under nitrogen. The reaction mixture was filtered and the benzene was evaporated. Solvents were purified by the usual methods.

\section{Cationic Polymerization}

Polymerizations were carried out in Schlenktype ampoules. Monomer and solvent were placed in the ampoule, which was then purged with dry nitrogen and cooled to the given polymerization temperature. A precooled catalyst solution was added. After a given period the polymerization was terminated by adding pyridine or methanol, and the mixture poured into excess methanol. The white powdery polymer obtained was purified by reprecipitation from benzene and methanol and then dried in vacuo at room temperature for one day.

When cationic polymerization was carried out at temperatures above $-40^{\circ} \mathrm{C}$, an insoluble cyclic trimer precipitated during polymerization, as shown later in this paper. It was separated from the reaction mixture by filtration and then the filtrate was poured into excess methanol to recover the soluble polymeric product. Characteristics of the cyclic trimer are given later.

\section{Other Polymerization Procedures}

The procedures are basically similar to that of cationic polymerization. Ziegler-type catalysts were prepared in toluene and aged at room temperature before polymerization. $\mathrm{AlEt}_{3}-$ $\mathrm{PhNHCOCH}_{3}$ catalyst was prepared by the reaction of $\mathrm{AlEt}_{3}$ with an equimolar amount of acetanilide at $20^{\circ} \mathrm{C}$ in toluene, according to the method of Tani, et al. ${ }^{6}$ Coordination polymerizations were terminated by pouring the reaction 


\section{Cyclopolymerization, Trimer of $o$-Formylphenylacetaldehyde}

mixture into methanol and the polymer was recovered. Anionic polymerizations were terminated by adding a THF solution of acetic anhydride. Formation and Characteristics of the Cyclic
Trimer

The following is one example of formation of a cyclic trimer. To a solution of $1 \mathrm{~g}$ of monomer in $5 \mathrm{ml}$ of methylene dichloride was added $\mathrm{BF}_{3} \mathrm{OEt}_{3}$ (1 mol \% of monomer) in methylene dichloride at $20^{\circ} \mathrm{C}$ in a Schlenk-type ampoule. Immediately a white product began to precipitate. The reaction mixture was kept at $20^{\circ} \mathrm{C}$ for $12 \mathrm{~min}$. Then the precipitate was filtered and washed with benzene and dried in vacuo. The filtrate and the benzene washings were combined and poured into excess methanol, but the polymer was not recovered in any appreciable quantity. The precipitate was insoluble in benzene and carbon tetrachloride, and slightly soluble in chloroform (solubility, $c a .5 \mathrm{mg} / l$ $\mathrm{m} l$ at $50^{\circ} \mathrm{C}$ ). Recrystallization from chloroform gave colorless needles: yield, 26\%; mp 284$285^{\circ} \mathrm{C}$.

Anal. Calcd for $\left(\mathrm{C}_{9} \mathrm{H}_{8} \mathrm{O}_{2}\right)_{3}: \mathrm{C}, 72.95 ; \mathrm{H}$, 5.44; mol wt, 444.

Found: C, 72.78; H, 5.42; mol wt, 442.

Attempted Copolymerization of Benzaldehyde and Phenylacetaldehyde

A portion of $2 \mathrm{~g}(0.019 \mathrm{~mol})$ of benzaldehyde and $2 \mathrm{~g}(0.017 \mathrm{~mol})$ of phenylacetaldehyde in 10 $\mathrm{ml}$ of toluene was placed in a Schlenk-type ampoule, and $\mathrm{BF}_{3} \mathrm{OEt}_{2}$ catalyst $(5 \mathrm{~mol} \%$ to monomer) was added at $-78^{\circ} \mathrm{C}$. When the reaction mixture was poured into excess methanol after $20 \mathrm{hr}$, only a trace amount of the resultant product was obtained. When anionic copolymerization of $1 \mathrm{~g}$ of benzaldehyde and $1 \mathrm{~g}$ of phenylacetaldehyde was carried out in $2 \mathrm{ml}$ of THF with $t$-BuOLi catalyst $(5 \mathrm{~mol} \%$ to monomer) at $-78^{\circ} \mathrm{C}$ for $12 \mathrm{~min}$, an insoluble product was obtained (yield, $0.15 \mathrm{~g}$ ). This product was shown by its infrared spectrum to be polyphenylacetaldehyde.

\section{Equipment}

Infrared and NMR spectra were obtained by using a JASCO Model IR-E spectrometer and a Varian Model A-60 spectrometer, respectively. In particular, an NMR spectrum of the cyclic trimer was obtained by connecting a spectro accumulator. An X-ray powder spectrum was taken with a Norelco (North American Phillips Co.). The molecular weights of the polymer and the trimer were measured with a vaporpressure osmometer (Mechrolab Model $301 \mathrm{~A}$ ) in benzene and chloroform, respectively, at $37^{\circ} \mathrm{C}$.

\section{RESULTS}

\section{Cyclopolymerization and Cyclooligomerization with} $\mathrm{BF}_{3} \mathrm{OEt}_{2}$ Catalyst

When a $\mathrm{BF}_{3} \mathrm{OEt}_{2}$ solution was added to a solution of $\boldsymbol{o}$-formylphenylacetaldehyde below $-60^{\circ} \mathrm{C}$, the polymerization system immediately turned pale yellow and then became colorless. Pertinent data (runs no. 1 to no. 4) are summarized in Table I. The polymer obtained was soluble in common organic solvents, such as benzene and chloroform, and softened at temperatures below $140^{\circ} \mathrm{C}$. The molecular weights of the polymers were rather low and the elemental analysis data were in accord with the calculated value.

Figure 1 a shows an IR spectrum of the polymer. Absorption peaks caracteristic of the acetal linkage are seen in the $930-1130 \mathrm{~cm}^{-1}$ region and the carbonyl groups disappears.

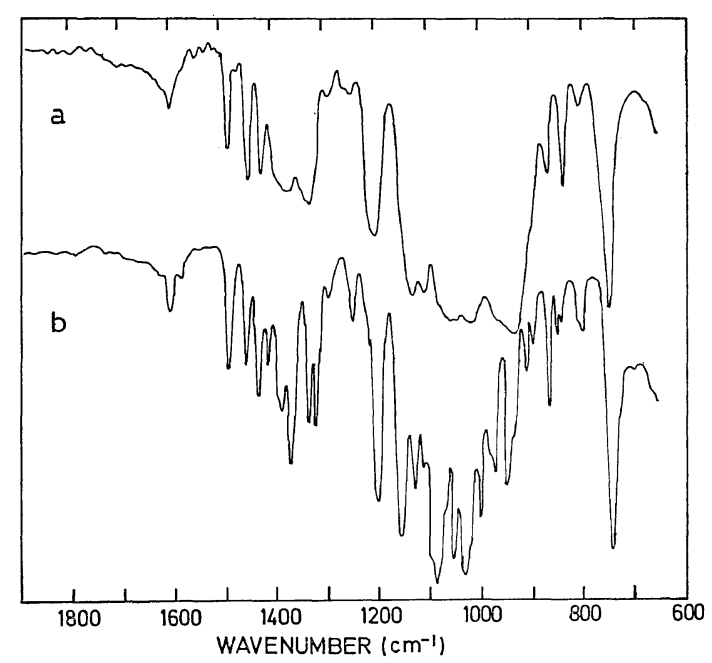

Figure 1. Infrared spectra of (a) poly (o-formylphenylacetaldehyde) obtained with $\mathrm{BF}_{3} \mathrm{OEt}_{2}$ catalyst at $-78^{\circ} \mathrm{C}(\mathrm{KBr}$ disc) and (b) cyclic trimer obtained at $-20^{\circ} \mathrm{C}$ ( $\mathrm{KBr}$ disc). 
Table I. Polymerization of $o$-formylphenylacetaldedyde and formation of cyclic trimer in the $\mathrm{BF}_{3} \mathrm{OEt}_{2}$-catalyzed system ${ }^{\mathrm{a}}$

\begin{tabular}{|c|c|c|c|c|c|c|}
\hline \multirow{2}{*}{$\begin{array}{l}\text { Run } \\
\text { No. }\end{array}$} & \multirow{2}{*}{$\begin{array}{l}\text { Monomer } \\
\text { concn, mol/l }\end{array}$} & \multirow{2}{*}{$\begin{array}{c}\text { Temp. } \\
{ }^{\circ} \mathrm{C}\end{array}$} & \multirow{2}{*}{$\begin{array}{c}\text { Time, } \\
\text { hr }\end{array}$} & \multirow{2}{*}{$\begin{array}{c}\text { Conversion, } \\
\% \\
\end{array}$} & \multicolumn{2}{|c|}{ Polymer or Trimer } \\
\hline & & & & & $\begin{array}{l}\text { Softening point, (melting } \\
\text { point) }{ }^{\circ} \mathrm{C}\end{array}$ & $\bar{M}_{n}$ \\
\hline 1 & 0.61 & -95 & 14 & 55 & $135-138$ & 1780 \\
\hline 2 & 0.60 & -78 & 15 & 52 & $135-140$ & $2000^{\mathrm{b}}$ \\
\hline 3 & $0.62^{\mathrm{c}}$ & -78 & 15 & 71 & $134-137$ & 2720 \\
\hline 4 & 0.61 & -60 & 14 & 30 & $120-125$ & 1660 \\
\hline 5 & 0.62 & -40 & 14 & $\left\{\begin{array}{l}20 \\
30^{d}\end{array}\right.$ & $\begin{array}{c}130-134 \\
(272-273)\end{array}$ & $\underline{1810}\}$ \\
\hline 6 & 0.63 & -20 & 13.6 & $81^{\mathrm{d}}$ & $(281-282)$ & 410 \\
\hline 7 & 1.1 & 0 & 15.5 & $64^{\mathrm{d}}$ & $(274-275)$ & 430 \\
\hline 8 & 1.4 & 20 & 0.2 & $26^{\mathrm{d}}$ & $(284-285)$ & 442 \\
\hline 9 & 0.61 & $\left\{\begin{array}{l}-78 \\
-20\end{array}\right.$ & $\left.10^{7.5}\right\}^{\mathrm{e}}$ & $\left\{\begin{array}{l}10 \\
68^{d}\end{array}\right.$ & $\begin{array}{c}107-110 \\
(278-279)\end{array}$ & $\left.\frac{620}{-}\right\}$ \\
\hline 10 & 0.61 & $\left\{\begin{array}{l}-20 \\
-78\end{array}\right.$ & $\left.\begin{array}{l}1 \\
7\end{array}\right\}^{\mathrm{e}}$ & $\left\{\begin{array}{l}14 \\
77 \mathrm{~d}\end{array}\right.$ & $\begin{array}{c}97-103 \\
(279-280)\end{array}$ & $\left.\begin{array}{l}610 \\
-\end{array}\right\}$ \\
\hline 11 & Polymer ${ }^{f}$ & 0 & 3.5 & $44^{d}$ & $(287-288)$ & 446 \\
\hline
\end{tabular}

a Solvent, $\mathrm{CH}_{2} \mathrm{Cl}_{2}$; Catalyst concn, $1 \mathrm{~mol} \%$.

b Anal. Calc'd for $\left(\mathrm{C}_{9} \mathrm{H}_{8} \mathrm{O}_{2}\right)_{n}$ : C, 72.95; H, 5.44. Found: C, 72.21; H, 5.42.

c Solvent, toluene.

d Crude cyclic trimer.

e Temperatures were varied during polymerization. The reaction mixture was kept first at $-78^{\circ} \mathrm{C}$ for $7.5 \mathrm{hr}$, then at $-20^{\circ} \mathrm{C}$ for $10 \mathrm{hr}$ in run no. 9; first at $-20^{\circ} \mathrm{C}$ for $1 \mathrm{hr}$, then $-78^{\circ} \mathrm{C}$ for $7 \mathrm{hr}$ in run no. 10 .

f A polymer was used instead of a monomer; concn, $0.1 \mathrm{~g} / \mathrm{m} / .2 \mathrm{~mol} \%$ of $\mathrm{BF}_{3} \mathrm{OEt}_{2}$ to a monomeric repeat unit was used.

These results strongly support the view that $o$ formylphenylacetaldehyde underwent cyclopolymerization to give a polymer consisting almost completely of the cyclized unit I, as illustrated in eq. 2.

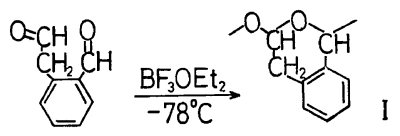

The cyclic structure $I$ is also supported by an NMR spectrum of the polymer (Figure 2a). Peaks ascribable to aldehype groups at around $10 \mathrm{ppm}$ were not observed, and three peak groups observed were assigned to the phenyl proton $(6.75-7.5 \mathrm{ppm})$, the methine proton $(5.0-6.57 \mathrm{ppm})$, and the methylene proton $(2.05-3.66 \mathrm{ppm})$. The area ratio of these peak groups was $4.0: 2.2: 1.8$, which was in close agreement with the calculated ratio $(4: 2: 2)$ for I.

When the cationic polymerization was carried out at temperatures above $-40^{\circ} \mathrm{C}$ (runs no. 5

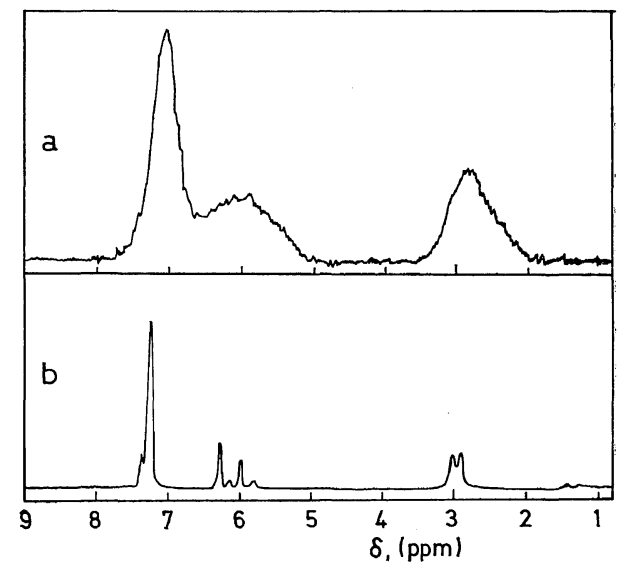

Figure 2. NMR spectra of (a) poly (o-formylphenylacetaldehyde) obtained with $\mathrm{BF}_{3} \mathrm{OEt}_{2}$ catalyst at $-78^{\circ} \mathrm{C}$ (in $\mathrm{CCl}_{4}$ ) and (b) cyclic trimer obtained at $-20^{\circ}$ (in $\mathrm{CDCl}_{3}$ ).

to no. 8) insoluble products with high melting points (usually over $270^{\circ} \mathrm{C}$ in the crude state) were invariably formed. The recrystallized product was concluded to be a trimer from molecular weight determination and elemental 
analysis (see experimental section).

In runs no. 9 and no. 10, the temperature was varied during polymerization. The result. of run no. 9 indicates that a large amount of a soluble polymer first produced at $-78^{\circ} \mathrm{C}$ was converted to the cyclic trimer at $-20^{\circ} \mathrm{C}$. On the other hand, the trimer first produced at $-20^{\circ} \mathrm{C}$ was not converted to the soluble polymer in run no. 10. In addition, the polymer was converted to the cyclic trimer when the polymer was treated with $\mathrm{BF}_{3} \mathrm{OEt}_{2}$ catalyst in methylene dichloride at $0^{\circ} \mathrm{C}$ (run no. 11, Table I). These results suggest that the very low solubility of the cyclic trimer made the reaction irreversible.

The general features of an IR spectrum of the trimer resemble that of the polymer, as seen in Figure 1. It is noted that peaks of the trimer sharper than those of the polymer are observed in the acetal linkage region (between 940 and $\left.1160 \mathrm{~cm}^{-1}\right)$. The absence of the carbonyl group in the trimer was also confirmed. Thus the structure of the trimer was considered to have a cyclic structure II, which can be readily constructed with the Stuart molecular model.

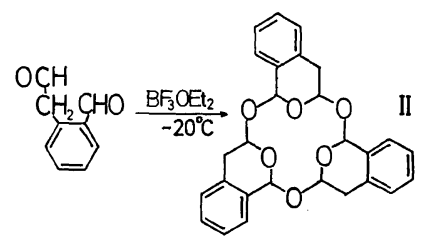

Figure $2 b$ shows an NMR spectrum of the trimer. The spectrum has four peaks assigned to the phenyl proton $(7.1 \mathrm{ppm})$, the acetal methine proton next to the phenyl group (6.27 $\mathrm{ppm})$, triplet), and the methylene proton (3.0 $\mathrm{ppm}$, doublet). The area ratio of these peaks is 4.3:0.9:1.0:1.8 in reasonable accord with the theoretical ratio $(4: 1: 1: 2)$ of the proposed structure II. The X-ray patterns demonstrate that the cyclic trimer is crystalline, as seen in Figure 3 , and $16 \AA$ of maximum spacing was estimated. Although many stereoisomers are conceivable for the trimer, the trimer obtained here probably consists of a single isomer having structure II, considering the data obtained: the sharp melting point, and IR, NMR, and X-ray

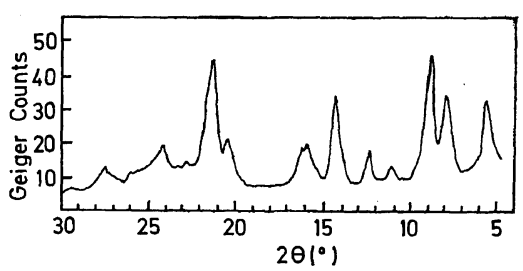

Figure 3. X-ray powder spectrum of cyclic trimer $\left(\mathrm{Cu}-\mathrm{K}_{\alpha}\right)$.

\section{diffraction data.}

\section{Cyclopolymerization with Anionic and Ziegler Catalysts}

Table II shows several polymerization results obtained with anionic, Ziegler, and other catalysts. All the polymers listed here were white powders and soluble in benzene and carbon tetrachloride. The degree of polymerization was low (about 8-25). It is interesting to note that the Zieger catalyst gave a soluble cyclopolymer at $0^{\circ} \mathrm{C}$, in contrast to the cationic polymerization. The polymers prepared at $-78^{\circ} \mathrm{C}$ and $0^{\circ} \mathrm{C}$ were concluded to be cyclopolymers I from their IR and NMR spectra. The spectral characteristics were almost identical to those of polymers prepared with $\mathrm{BF}_{3} \mathrm{OEt}_{2}$ catalyst.

On the other hand, $t$-BuOLi catalyst did not give any polymer at $0^{\circ} \mathrm{C}$, but gave a cyclopolymer containing small amounts of the aromatic aldehyde group at $-78^{\circ} \mathrm{C}$ at a low yield (No. 17 and 18 in Table II). The IR absorption of the aliphatic aldehyde group was almost undetectable. The content of the pendent aromatic aldehyde group in the polymer was estimated, from the intensity of the IR peak at $1700 \mathrm{~cm}^{-1}$, to be less than $10 \%$. Thus it can be assumed that a growing anion first attacks possibly more reactive aliphatic aldehyde and the addition of less reactive aromatic aldehyde ensues to form a cyclic structure. The possibility of the existence of the aromatic aldehyde group at the polymer chain end should not be excluded.

Triethylaluminum catalyst was not effective at $-78^{\circ} \mathrm{C}$, but gave a polymer when the polymerization was carried out at $0^{\circ} \mathrm{C}$ or at $-78^{\circ} \mathrm{C}$ after keeping the polymerization mixture at $0^{\circ} \mathrm{C}$ for $30 \mathrm{~min}$, as shown in Table II. An IR spectrum of the polymer showed absorption 


\section{S. TAgami, T. Kagiyama, and C. Aso}

Table II. Polymerization of $o$-formylphenylacetaldehyde with several catalysts

\begin{tabular}{|c|c|c|c|c|c|c|c|c|c|}
\hline \multirow{2}{*}{$\begin{array}{l}\text { Run } \\
\text { No. }\end{array}$} & \multirow{2}{*}{ Catalyst } & \multirow{2}{*}{$\begin{array}{l}\text { Concn, } \\
\text { mol \% }\end{array}$} & \multirow{2}{*}{ Solvent } & \multirow{2}{*}{$\begin{array}{l}\text { Monomer } \\
\text { concn. } \\
\text { mol/l }\end{array}$} & \multirow{2}{*}{$\begin{array}{c}\text { Temp, } \\
{ }^{\circ} \mathrm{C}\end{array}$} & \multirow{2}{*}{$\begin{array}{c}\text { Time, } \\
\text { hr }\end{array}$} & \multirow{2}{*}{$\begin{array}{c}\text { Conver- } \\
\text { sion, } \\
\%\end{array}$} & \multicolumn{2}{|c|}{ Polymer } \\
\hline & & & & & & & & $\begin{array}{l}\text { Softening } \\
\text { point, }{ }^{\circ} \mathrm{C}\end{array}$ & $\bar{M}_{n}$ \\
\hline 12 & $\mathrm{AlEt}_{3} / \mathrm{TiCl}_{4}(2 / 1)$, & $\mathrm{Al}: 5$ & Toluene & 1.1 & -78 & 15 & $83^{a}$ & $148-153$ & 2120 \\
\hline 13 & $\mathrm{AlEt}_{3} / \mathrm{TiCl}_{4}(2 / 1)$, & $\mathrm{A} 1: 5$ & Toluene & 1.1 & 0 & 9 & 34 & $143-145$ & 3660 \\
\hline 14 & $\mathrm{AlEt}_{3} / \mathrm{TiCl}_{4}(3 / 1)$, & $\mathrm{A} 1: 5$ & Toluene & 1.1 & 0 & 16 & 53 & $144-143$ & 2070 \\
\hline 15 & $\mathrm{AlEt}_{3} / \mathrm{PhNHCOCH}_{3}$ & ${ }_{3}^{\mathrm{c}} \mathrm{Al}: 5$ & Toluene & 0.8 & -78 & 15 & 13 & $112-119$ & - \\
\hline 16 & $\mathrm{AlEt}_{3} / \mathrm{PhNHCOCH}_{3}$ & ${ }_{3}^{\mathrm{c}} \mathrm{Al}: 5$ & Toluene & 0.8 & 0 & 15.5 & 57 & $135-140$ & - \\
\hline 17 & $t$-BuOLi & 2.5 & THF & 1.8 & -78 & 15 & $9 \mathrm{~b}$ & $131-135$ & 1170 \\
\hline 18 & $t$-BuOLi & 2.5 & THF & 1.8 & 0 & 15 & 0 & - & - \\
\hline 19 & $\mathrm{AlEt}_{3}$ & 5 & Toluene & 1.7 & $\left\{\begin{array}{r}0 \\
-78\end{array}\right.$ & $\left.\begin{array}{c}0.5 \\
15\end{array}\right\}$ & 71 & $80-95$ & - \\
\hline 20 & $\mathrm{AlEt}_{3}$ & 5 & Toluene & 1.5 & -78 & 15 & 0 & - & - \\
\hline 21 & $\mathrm{AlEt}_{3}$ & 5 & Toluene & 1.5 & 0 & 15 & 10 & $130-136$ & 1980 \\
\hline
\end{tabular}

a Anal. Calcd for $\left(\mathrm{C}_{9} \mathrm{H}_{8} \mathrm{O}_{2}\right)_{n}$ : C, 72.95; H, 5.44. Found C, 72.98; H, 5.56.

b Anal. Found: C, 71.76; H, 5.33.

c Catalyst developed by Tani, et al. ${ }^{6}$

bands similar to those of other polymers described above in the ether linkage region (1150$\left.900 \mathrm{~cm}^{-1}\right)$. However, the increase in the observed ratio of $D_{1452} \mathrm{~cm}^{-1} / D_{1492} \mathrm{~cm}^{-1}$ in the spectrum suggested the increase in the methylene group content in the polymer structure. In addition, the IR spectrum of the polymer shows a sharp peak at $1730 \mathrm{~cm}^{-1}\left(\nu_{\mathrm{C}=0}\right)$ and no peak at $2760 \mathrm{~cm}^{-1}\left(\nu_{\mathrm{C}-\mathrm{H}}\right.$ of aromatic aldehyde). These results probably demonstrate the presence of an ester group produced by a Tischenko-type reaction in addition to the cyclic ether unit I. Tischenko-type polymerizations of dialdehydes have been known in some cases ${ }^{7-9}$. Yokota and coworkers ${ }^{10}$ reported the coexistence of the ester group and the cyclic ether group in polyglutaraldehyde prepared with aluminum $t$-butoxide at polymerization temperatures over $0^{\circ} \mathrm{C}$. Since the polymerization mixture of $o$ formylphenylacetaldehyde was made to react at $0^{\circ} \mathrm{C}$, it was considered that triethylaluminum probably changed to the alkoxide derivative and then the Tischenko-type reaction proceeded partially.

Triethylaluminum-acetanilide catalyst was also effective, as seen in Table II. It gave a cyclopolymer containing small amounts of the aldehyde group (which consisted of aromatic aldehyde and less aliphatic groups) at $-78^{\circ} \mathrm{C}$, but gave a cyclopolymer containing small amounts of ester-type carbonyl group at $0^{\circ} \mathrm{C}$. The latter result suggests that the Tischenko- type reaction possibly proceeded partially in this system.

\section{DISCUSSION}

The copolymerization of benzaldehyde and phenylacetaldehyde was attempted in order to compare it with the polymerization of $o$-formylphenylacetaldehyde, since the latter monomer possesses aldehyde groups common to benzaldehyde and phenylacetaldehyde in the ortho position. However, only a trace amount of product was obtained under cationic copolymerization conditions at $-78^{\circ} \mathrm{C}$, while $t$-BuOLi gave only a homopolymer of phenylacetaldehyde, as shown in eq 4 . Thus the high polymerizability

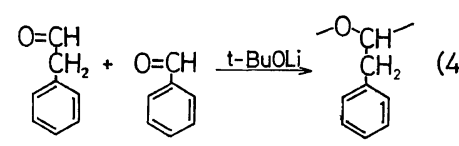

of $o$-formylphenylacetaldehyde with $t$-BuOLi and $\mathrm{BF}_{3} \mathrm{OEt}_{2}$ catalysts at $-78^{\circ} \mathrm{C}$ is ascribed to the ease of intramolecular cyclization.

In a previous paper $^{2}$, we proposed two types of cyclization schemes for the cationic cyclopolymerization of $o$-phthalaldehyde. One of them was an intermediate type, where the cation derived by the addition of a propagating cation to a monomer was stabilized by the neighboring aldehyde group. The other was a concerted 


\section{Cyclopolymerization, Trimer of $o$-Formylphenylacetaldehyde}

cyclization. The overwhelming cyclization observed in the cationic polymerization of $o$-formylphenylacetaldehyde suggests an analogous mechanism. Since the aliphatic aldehyde group is considered to be more reactive and basic than the aromatic aldehyde group, it is inferred that a propagating cation attacks the aliphatic aldehyde group preferentially and the neighboring aromatic aldehyde group in the same monomer molecule participates in polymerization through an intermediate state (III) or in a concerted manner (IV).

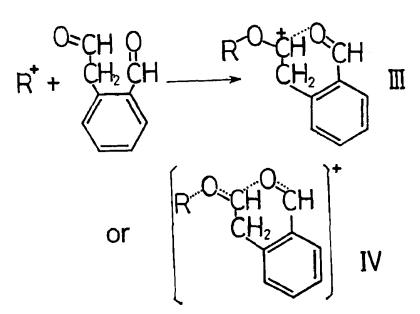

Many aliphatic monoaldehydes have been known to form cyclic oligomers, such as trioxane, paraacetaldehyde and others, under suitable reaction conditions. ${ }^{11}$ Prior to the present study, however, the cyclic oligomer of dialdehydes had been unknown. Thus the formation of the cyclic trimer II composed of several fused rings is of considerable interest and, at the same time, suggests the possible formation of cyclic oligomers from other dialdehydes which are capable of cyclopolymerization.

The fact that the trimer obtained here has no pendent aldehyde group appears to be associated with the high cyclopolymerizability of $o$-formylphenylacetaldehyde at low temperatures. At higher temperatures, the cyclic trimer was the preferred product. The ceiling temperature for cyclopolymerization, as discussed in the cationic polymerization of $o$-phthalaldehyde, ${ }^{1,12}$ may be taken into consideration as one of the reasons why a polymer was not produced at high temperatures. However, the fact that the Ziegler catalyst gave a soluble polymer without formation of the trimer even at $0^{\circ} \mathrm{C}$ (see the previous section) discredits this supposition. Two possible mechanisms may be considered to explain the formation of the cyclic oligomer. One is an acid-catalyzed trimerization as shown in eq 6. The other is the formation of the trimer by back-biting of the propagating chain, as illustrated in eq 7 .
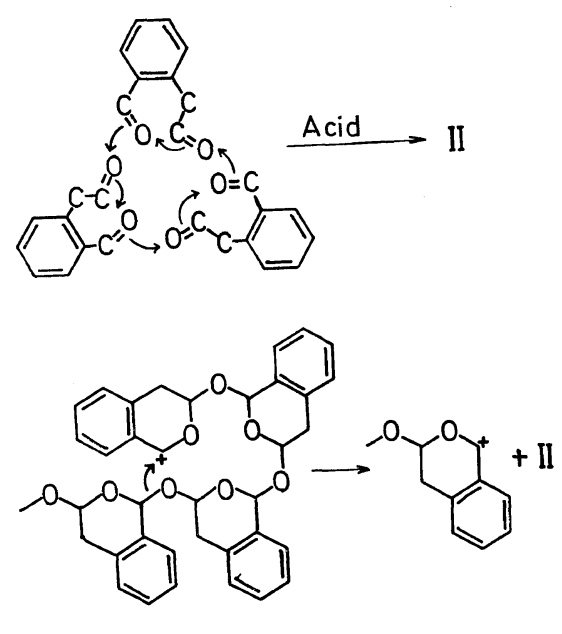

Since the polymer was converted to the cyclic trimer II at $0^{\circ} \mathrm{C}$ (Run no. 11, Table I), we consider the back-biting mechanism preferable. It is conceivable that the very low solubility of the cyclic trimer made the conversion irreversible and the trimer was obtained as a kinetic product.

In the formation of cyclic trimers of aliphatic monoaldehydes, it was pointed out that the closure to a 6-membered ring would be sterically favored by the presence of bulky substituents. ${ }^{11}$ Although the cyclic trimer II obtained here is 12 -membered, the isochroman ring produced by intramolecular cyclization seems to render formation of the 12-membered ring sterically favorable. Considering the ease of the trimer formation, the steric effect due to a bulky repeat unit of polymer, and the probable presence of the back-biting reaction, the possibility that the polymer obtained here also consists of a large ring may not be excluded. The relationship between trimerization and polymerization of $o$-formylphenylacetaldehyde is not yet clear and, together with the steric structure of the trimer, is now being studied further.

Acknowledgment. We are grateful to Dr. T. Kunitake of our research group for many valuable discussions. We also wish to thank 
Mr. K. Imada for his valuable advice during the investigations into the structure of the trimer.

\section{REFERENCES}

1. C. Aso, S. Tagami, J. Polym. Sci., Part B, 5, 217 (1967).

2. C. Aso, S. Tagami, T. Kunitake, J. Polym. Sci., 7, 497 (1969).

3. C. Aso, S. Tagami, T. Kunitake, Polymer J., 1, 395 (1970).

4. B. K. Blount, R. Robinson, J. Chem. Soc., 555 (1933).

5. S. Roberts, R. M. Winstein, J. Amer. Chem. Soc., 75, 2297 (1953).
6. H, Tani, H. Yasuda, T, Araki, J. Polym. Sci., Part B, 2, 933 (1964).

7. Y. V. Mitin, Y. N. Sazanox, G. P. Vlasox, M. M, Koton, Vysokomol. Soedin., 2, 716 (1960).

8. J. N. Koral, E. M. Smolin, J. Polym. Sci., Part A-1, 2931 (1953).

9. K. Yokota, Y. Ito, Y. Ishii, Kogyo Kagaku Zasshi (J. Chem, Soc. Japan, Chem. Ind. Sect.), 66, 1112 (1963).

10. K. Yokota, Y. Suzuki, Y. Ishii, Kogyo Kagaku Zasshi (J, Chem. Soc. Japan, Chem. Ind, Sect,), 68, 2459 (1965).

11. J. Furukawa, T. Saegusa, "Polymer Reviews," Vol. 3, Interscience Publishers, New York, N. Y., 1963, p 46.

12. C. Aso, S. Tagami, T. Kunitake, J. Polym. Sci., 8, 1323 (1970). 